\title{
Efficacy of early skin-to-skin contact on the rate of exclusive breastfeeding in term neonates: a randomized controlled trial.
}

\author{
Detroit Medical Center, Neonatology
}

\author{
Amit Sharma
}

\begin{abstract}
Background: Despite multiple benefits of breast milk, the rates of exclusive breastfeeding in developing countries are low. Objective: To evaluate the efficacy of early skin -to -skin contact (SSC) on the rate of exclusive breastfeeding (EBF) at 6 weeks of age among term neonates born by vaginal delivery.

Methods: Term neonates born by vaginal delivery and did not require any resuscitation were randomized at birth to SSC $(n=100)$ and control $(n=100)$ group. Immediately after clamping the umbilical cord, SSC group neonates were placed on the bare bosom of mother and control group neonates were placed under a radiant warmer for a period of 45 minutes each while mothers underwent management of the third stage of labor and episiotomy repair. Pain experienced by mother during episiotomy repair was recorded using a numerical pain scale The primary outcome evaluated was the rate of exclusive breastfeeding at 6 weeks of postnatal age.

Results: A significantly higher proportion of neonates were exclusively breastfeed at 6 weeks of age in the SSC group than in the control group $(72 \%$ vs. $57.6 \%, \mathrm{p}=0.04$, relative risk: $1.3,95 \%$ confidence interval: $1.0-1.6)$. The pain score during episiotomy repair in mothers of the SSC group was significantly lower than the control group $(4.74 \pm 0.85$ versus $5.34 \pm 0.81 ; \mathrm{P}<0.01)$.

Conclusions: Early SSC significantly improved the rate of exclusively breastfeeding at 6 weeks of age among healthy term neonates. An important additional effect was a decrease in the amount of pain that mothers in the SSC group experienced during episiotomy repair.
\end{abstract}

Keywords: Early skin-to-skin contact, exclusive breastfeeding in term neonates, randomized controlled trial.

DOI: http://dx.doi.org/10.4314/ahs.v16i3.20

Cite as: Sharma A. Efficacy of early skin-to-skin contact on the rate of exclusive breastfeeding in term neonates: a randomized controlled trial. Afri Health Sci 2016;16(3): 790-797. DOI: http:/ / dx.doi.org/10.4314/abs.v16i3.20

\section{Introduction}

Breast feeding (BF) is a critical factor for infants' health and survival. ${ }^{1}$ Breast milk provides species and age specific nutrients with best nutritional balance for them..$^{2-4} \mathrm{It}$ has been shown that breast milk improves the nutritional status of young children, reduces morbidity and mortality, and when initiated early, can reduce neonatal mortality by one -fourth. ${ }^{5,6}$ Despite multiple benefits from breast milk, only an estimated one -fourth of neonates in India were breastfed within the first hour of life and less than half are exclusively breastfed at six months of age. ${ }^{6}$

Early Skin -to -skin contact (SSC), which is placing the naked baby prone on the mother's bare chest soon after birth, has been recommended as an important component of care immediately after birth and is included as a

\section{Corresponding author: \\ Amit Sharma, \\ Detroit Medical Center, Neonatology \\ Email: dramit55555@gmail.com}

African Health Sciences Vol 16 Issue 3, September 2016 requirement in the World Health Organization / United Nations children's fund's (WHO/ UNICEF) Baby Friendly Hospital Initiative (BFHI). ${ }^{7}$

The first 2 hours post birth, when infants are most responsive to tactile, thermal, and odor clues from their mothers, is defined as the optimal time for them to initiate breastfeeding behavior, such as rooting and sucking. ${ }^{8}$ SSC creates an optimal environment for adaptation of newborn infants to extra -uterine life. In addition to providing warmth, it facilitates attachment to the breast and improves bonding/attachment. ${ }^{9}$ Infants having SSC with their mothers have been shown to display more efficient sucking patterns. ${ }^{10}$

Previous studies have suggested that early SSC increases the rate of exclusive breastfeeding $(\mathrm{EBF})$ and $\mathrm{BF}$ duration. ${ }^{11,12}$ In general, at birth neonates are wrapped in layers of clothes and allowed rooming in with mother as part of standard of care in India and mothers are informed about 6 months of exclusive BF.

This current study aims to evaluate the efficacy of early SSC on rate of exclusive breastfeeding at 6 weeks of age 
in our hospital setting. Additionally, this study investigates the effect of SSC on episiotomy repair pain in mothers, a relationship not clearly defined in the literature.

\section{Method}

This prospective, open -label, randomized controlled trial was conducted from May 1, 2008 to September 30, 2009 at Government medical college, Chandigarh, a tertiary hospital in Northern India. We enrolled term neonates born by vaginal delivery and who did not require initial steps of resuscitation, (as per the Neonatal Resuscitation Algorithm of the American Academy of Pediatrics ) in the presence of the investigator. We excluded neonates with major congenital malformations, born by breech, ventouse or forcep delivery, contraindications for breast feeding, product of multiple pregnancies, those born to known HIV-seropositive mothers, mothers that refuse to breastfeed, or mothers unable to come for follow up at 6 weeks postpartum

A random number sequence was generated using a computer program. Block randomization was used with a fixed block size of four. Concealment of allocation was ensured by using serially numbered, opaque envelopes that were sealed.

Written consent was obtained from each mother after a decision of anticipated vaginal delivery was taken by obstetrician. If the neonate met the inclusion criteria, a sealed envelope was opened immediately, and then the neonate was allocated to the SSC or the Control group within 1 minute of birth.

After clamping the umbilical cord, SSC group neonates were placed in prone position on the bare bosom of mother, and the control group neonates were placed under a radiant warmer for a period of 45 minutes each with caps, but no diapers. Mothers at this time underwent management of the third stage of labor and episiotomy repair.

After these interventions, neonates were wrapped in two layers of clothes and allowed rooming in with mother.

The pain of episiotomy repair experienced by mother was recorded by the investigator himself using a numerical visual pain scale at the end of procedure. ${ }^{13}$ This pain scale has been validated by American Cancer society for routine recording of subjective pain. Local infiltration with $2 \%$ lignocaine hydrochloride was used during episiotomy. Vital monitoring including heart rate, respiratory rate and axillary temperature (digital thermometer Model DT $-101 \mathrm{~N}$, Hicks thermometer) of the infant, were recorded at birth, at 10 minutes, 30 minutes and 6 hours of life, then subsequently every 6 hours for first 24 hours of life by investigator or nursing staff. The delivery rooms were centrally air conditioned with temperature $22-26$ degree centigrade. The frequency of micturition and defecation were recorded by mother on pretested proforma and confirmed by the investigator himself during each vital monitoring without any intention to treat.

At 24 hours, length and occipito -frontal circumference were obtained using a Mediserve infantometer and fiberglass non -stretchable tape respectively. Before discharge, routine counseling regarding breastfeeding was done by a medical social worker blinded to study group allocation. In addition, mother and neonatal baseline characteristics were recorded such as education level, previous BF experience, age, parity status, duration of EBF in last sibling, gestation and birth weight. Mother-infant dyads were discharged from hospital 24 hours after birth. During this 24 hour period, mothers were trained to record their weekly BF status each Sunday. Mothers were given a printed proforma describing each class of $\mathrm{BF}$ as follows: $\mathrm{EBF}$, predominant BF (1 -2 supplemental feed/24 hours), mixed feeding (breastfeed plus $>2$ supplemental feeds $/ 24$ hours and total supplemental feeding). Parents were also contacted by telephone on weekly basis to record feeding status by investigator and to encourage filling the proforma.

The rate of EBF at 6 weeks of age (primary outcome) was recorded at the time of first immunization visit in the follow -up clinic. The analysis of the primary outcome was made according to the protocol. Parents were contacted by telephone one week prior to remind them regarding their visit and also to bring their BF status proforma. BF status was accessed by reviewing the proforma and also by comparing with our telephone records. Anthropometry (weight, length and occipito -frontal circumference) was also recorded during this visit. The Ethics Committee of the hospital approved the protocol and the study was registered with the Clinical Trials Registry (clinicaltrials.gov, registration No. CTRI/2013/06/003720).

African Health Sciences Vol 16 Issue 3, September 2016 


\section{Statistical analysis}

Data was analyzed using Epi info software (version 3.4.3, Centre of disease control, CDC, Athens). Categorical data was analyzed using chi -square or Fischer's exact test. Continuous data was analyzed using $\mathrm{t}$-test or Mann -Whitney test as applicable. $P$ valve of $<0.05$ was considered significant

To determine the sample size, we used data from a pilot study done at our Department showing the rate of exclusive breastfeeding $47 \%$ at 6 weeks of age. The hypothesis was to increase the rate from $50 \%$ to $75 \%$. With two sid- ed alpha of 0.05 and $90 \%$ power, 85 subjects were needed in each group. To account for the loss of follow -up, plan was to enroll 100 subjects in each group.

\section{Results}

During the study period, a total of 853 eligible neonates were born. Out of these, 624 mothers were unable to come for follow -up at 6 weeks post -partum, and 29 refused consent. A total of 200 neonates were enrolled and randomized to the SSC $(n=100)$ or Control group $(n=100)$ and one neonate lost from control group was not included in the analysis (figure 1).

\section{Figure 1: Flow Diagram}

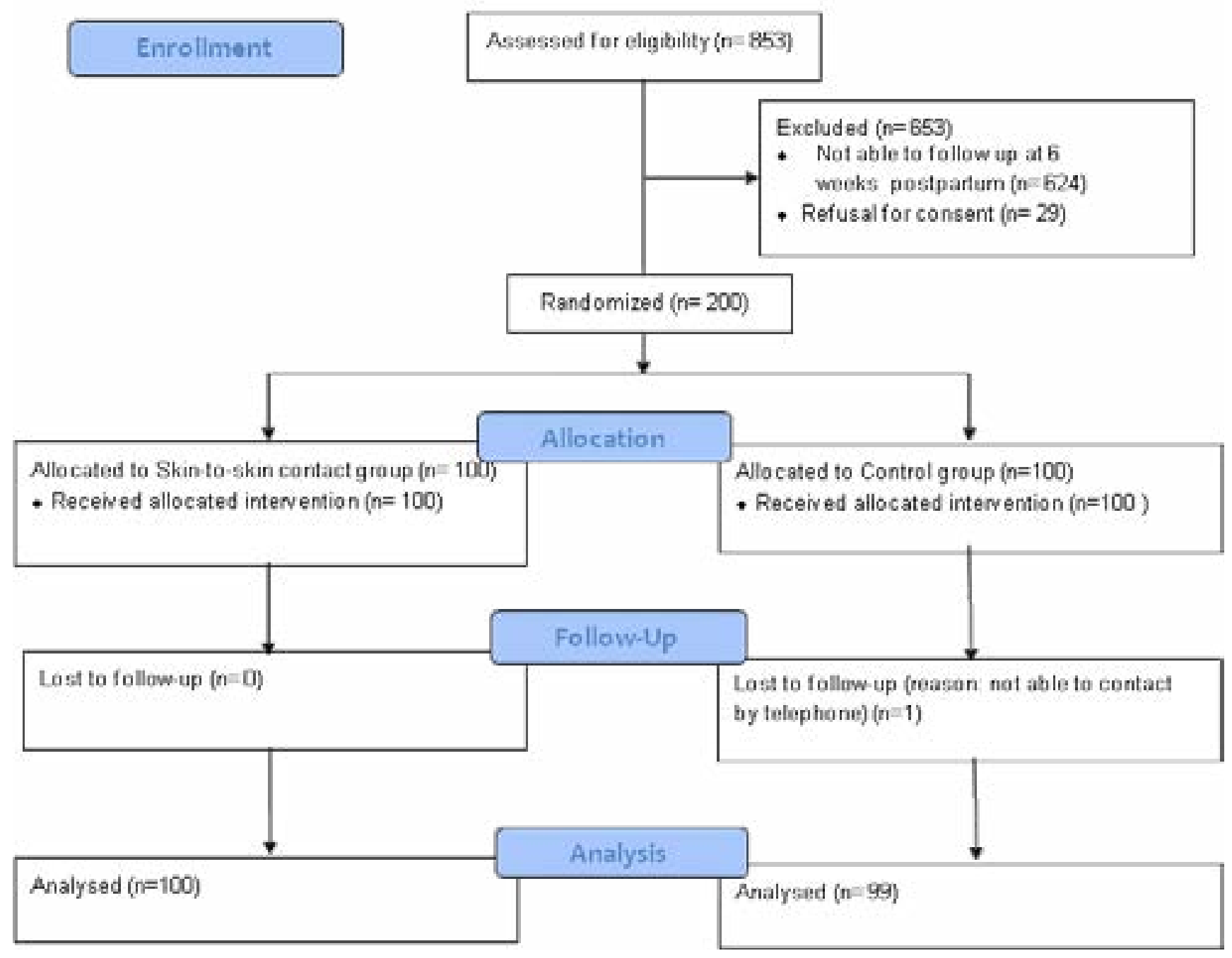


Table I: Maternal and Neonatal baseline variable

\begin{tabular}{|c|c|c|c|}
\hline Variable & $\begin{array}{l}\text { SSC group } \\
(\mathbf{n}=\mathbf{1 0 0})\end{array}$ & $\begin{array}{c}\text { Controlgroup } \\
(n=99)\end{array}$ & Pvalve \\
\hline Parity status $\Phi$ & $1(1-2)$ & $1(1-1)$ & 0.84 \\
\hline Age of mother (years)* & $24.9 \pm 3.5$ & $24.8 \pm 3.3$ & 0.77 \\
\hline Education qualification & & & \\
\hline Illiterate & & & \\
\hline below matriculation & $17(17 \%)$ & $13(13 \%)$ & \\
\hline matriculation & $36(36 \%)$ & $38(38 \%)$ & 0.81 \\
\hline graduate & $28(28 \%)$ & $29(29 \%)$ & \\
\hline postgraduate & $13(13 \%)$ & $17(17 \%)$ & \\
\hline At least 3 antenatal check-ups & $44(44 \%)$ & $44(44 \%)$ & 1.0 \\
\hline $\begin{array}{l}\text { Duration of exclusive breastfeeding } \\
\text { in last sibling (months) } *\end{array}$ & $4.4 \pm 1.9$ & $4.8 \pm 1.7$ & 0.52 \\
\hline Breast feeding experience & $22(22.5 \%)$ & $25(25.5 \%)$ & 0.62 \\
\hline Episiotomy & $98(98 \%)$ & $100(100 \%)$ & 0.16 \\
\hline Neonate gestation in completed weeks $\uparrow$ & $38(37-39)$ & $38(37.5-39)$ & 0.38 \\
\hline $\begin{array}{l}\text { Neonate Anthropometry at birth } \\
\text { a. Weight (grams)* }\end{array}$ & $2764 \pm 317$ & $2796 \pm 340$ & 0.49 \\
\hline b. Length $(\mathrm{cm}) *$ & $48.9 \pm 1.4$ & $49.0 \pm 1.0$ & 0.43 \\
\hline c. Occipito-frontal circumference $(\mathrm{cm}) *$ & $33.3 \pm 0.7$ & $33.3 \pm 0.7$ & 0.72 \\
\hline
\end{tabular}

\section{Study outcomes}

A significantly higher proportion of neonates were EBF at 6 weeks of age in the SSC group as compared to the
Control group ( $72 \%$ vs. $57.6 \%, \mathrm{p}=0.04$, relative risk: 1.3 , 95\% confidence interval: $1.0-1.6$ ) (table II). 
Table II: Primary and Secondary outcomes

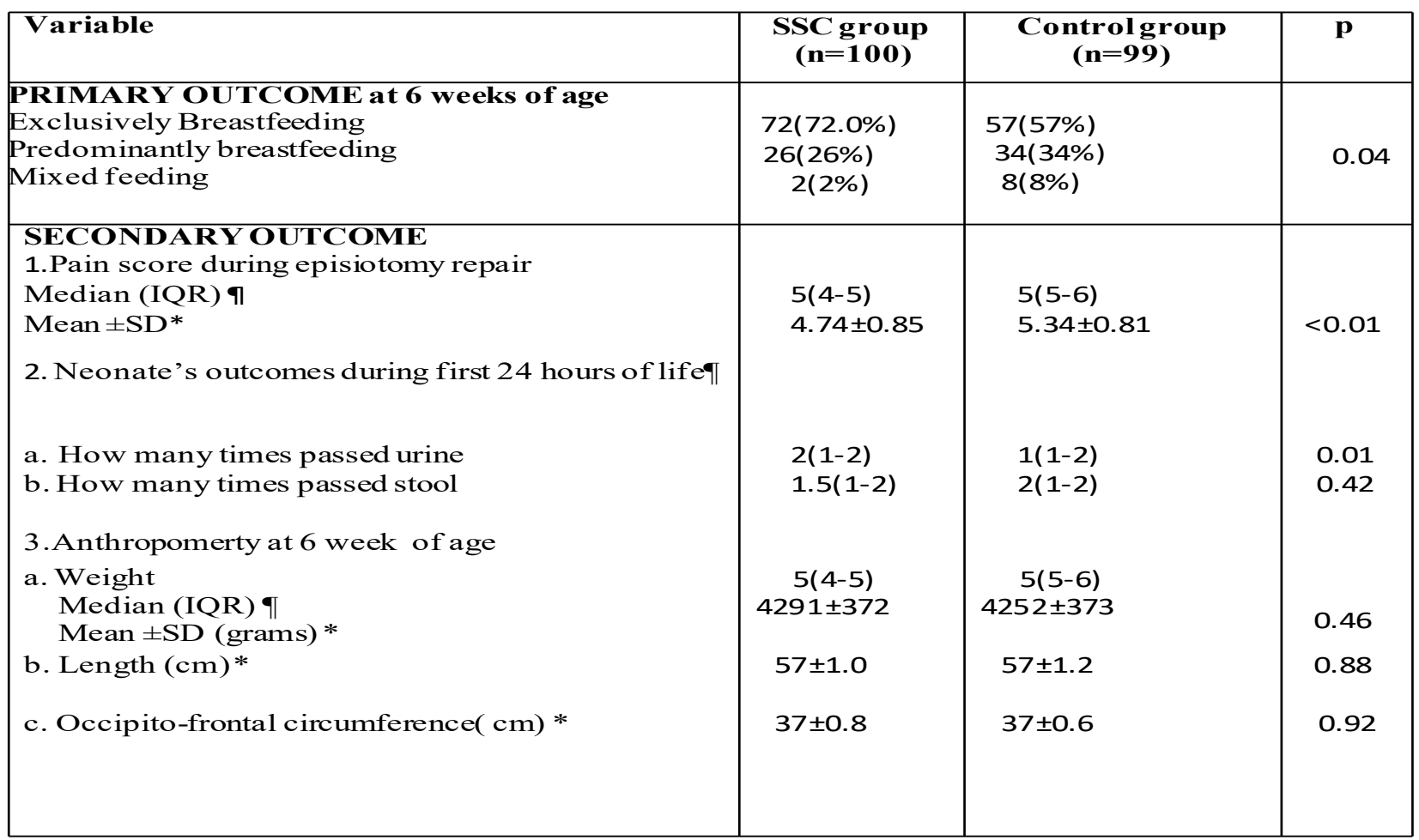

Valves expressed as *Mean $\pm \mathrm{SD}$, number (percentage), $\| \mathrm{IQR}=$ interquartile range, $\mathrm{SD}=\mathrm{standard}$ deviation, percentage $(\%), \mathrm{BF}=$ breastfeed

The mean pain score during episiotomy repair in mothers of the SSC group was significantly lower than the control group $(4.74 \pm 0.85$ versus $5.34 \pm 0.81 ; \mathrm{p}<0.01)$.

The number of micturition episodes observed in the SSC group over the first 24 hours of life was significantly higher than the control care group $(\mathrm{p}=0.01)$. Both groups were comparable with respect to the number of stools passed in the first 24 hours of life $(p=0.42)$. No significant difference was found in vital signs (heart rate, respiratory rate and axillary temperature) in the first 24 hours of life between both groups (table III).

\section{Table III: Secondary outcomes: neonatal vital in first 24 hours of life}

\begin{tabular}{|c|c|c|c|c|c|c|c|c|c|}
\hline \multirow[t]{2}{*}{ Age } & \multicolumn{3}{|c|}{ Heart rate(per minute) } & \multicolumn{3}{|c|}{ Respiratory rate(per minute) } & \multicolumn{3}{|c|}{ Temperature(degree F) } \\
\hline & \multicolumn{3}{|c|}{ SSC (n=100) Control (n=99) P valve } & \multicolumn{3}{|c|}{ SSC (n=100) Control $(n=99)$ P valve } & \multicolumn{3}{|c|}{ SSC $(n=100)$ Control $(n=99)$ P valve } \\
\hline Birth & $163.0 \pm 5.4$ & $162.8 \pm 4.6$ & 0.83 & $64 \pm 3.0$ & $64 \pm 4.0$ & 0.65 & $97.1 \pm 0.18$ & $97.1 \pm 0.20$ & 0.60 \\
\hline 10minutes & $154.5 \pm 4.9$ & $154.3 \pm 4.5$ & 0.72 & $57 \pm 4.0$ & $58 \pm 4.1$ & 0.24 & $97.5 \pm 0.20$ & $97.5 \pm 0.22$ & 0.88 \\
\hline 30minutes & $140.6 \pm 3.6$ & $141.1 \pm 3.9$ & 0.32 & $44 \pm 3.8$ & $45 \pm 4.0$ & 0.58 & $98.5 \pm 0.13$ & $98.5 \pm 0.14$ & 0.13 \\
\hline 6 hours & $140.5 \pm 3.7$ & $140.2 \pm 3.7$ & 0.61 & $44 \pm 3.5$ & $44 \pm 4.4$ & 0.52 & $98.5 \pm 0.13$ & $98.5 \pm 0.18$ & 0.17 \\
\hline 12 hours & $140.1 \pm 3.1$ & $141.0 \pm 10.5$ & 0.45 & $44 \pm 3.3$ & $43 \pm 3.5$ & 0.56 & $98.5 \pm 0.14$ & $98.5 \pm 0.13$ & 0.69 \\
\hline 18 hours & $147.1 \pm 4.0$ & $146.9 \pm 4.3$ & 0.67 & $51 \pm 4.4$ & $52 \pm 4.3$ & 0.17 & $98.0 \pm 0.21$ & $98.0 \pm 0.23$ & 0.46 \\
\hline 24 hours & $142.4 \pm 4.2$ & $142.2 \pm 4.1$ & 0.65 & $46 \pm 3.8$ & $46 \pm 3.9$ & 0.80 & $98.4 \pm 0.17$ & $98.5 \pm 0.12$ & 0.87 \\
\hline
\end{tabular}


There was also no significant difference between Page 12 of 22 ScholarOne, 375 Greenbrier Drive, Charlottesville, VA, 22901 Workflow 0 For Peer Review 9 the anthropometry (weight, length and occipito -frontal circumference) at 6 weeks of age in the SSC group when compared to the control care group (table II).

\section{Discussion}

We found that early SSC have a long -lasting impact on the rate of exclusive breastfeeding at 6 weeks postpartum. Our results proved in concordance with the systematic review by the Cochrane neonatal review group. ${ }^{11,12}$ This review included 1925 participants enrolled in thirty studies. Statistically significant beneficial effects of early SSC were observed in the form of improved rate of exclusive breastfeeding at one to four months postpartum (odds ratio: $1.82,95 \%$ confidence interval 1.08 to 3.07 ), and increased breastfeeding duration (weighted mean difference: $42.55,95 \%$ CI -1.69 to 86.79$)$.

The possible explanation for these findings are the high levels of catecholamine levels immediately postbirth that makes olfactory bulbs in the infant's nares extremely sensitive to the odor cues. ${ }^{14,15}$ When SSC is initiated immediately after birth, these physiological changes helps the full term infant to crawl unaided towards the mother's nipple and latch correctly within about 60 minutes. ${ }^{16,17}$ The first 2 hour postbirth, most infants often become sleepy and difficult to arouse, probably secondary to a decrease in circulating catecholamine level. ${ }^{18}$

Thukral et al. and Srivastava et al. both found similar effect of SSC on EBF at 6 week postpartum. ${ }^{19,20}$ In contrast , Moore et al . and Carfoot et al. were not able to find any statistically significant effect of SSC on breastfeeding status at 1 month postpartum and 4 month postpartum respectively. ${ }^{21,22}$

SSC is found to be associated with greater level of maternal breastfeeding self-efficacy, satisfaction and confidence in mother's ability to breastfeed and care for her infant. ${ }^{20,23}$ Aghdas et al . also found an enhanced maternal breastfeeding self-efficacy from SSC. ${ }^{24}$ In another study by Carfoot et al ., mothers enjoyed the experience of SSC and preferred it for future pregnancy. ${ }^{22}$ Altogether, these factor may increase exclusive breastfeeding duration, along with enhanced maternal -baby bonding.
Interestingly, Bystrova et al . revealed that early SSC has positive influence on mother -infant interaction at 1 year after birth secondary to enhanced bonding during early infancy. ${ }^{25}$

Our study also found that the mean maternal pain score during episiotomy repair was significantly lower in the SSC group in contrast to study by Gabriel et al ., which did not revealed a statistically significant effect of SSC on episiotomy repair. ${ }^{26}$

There is very limited literature about effect of SSC on this variable. This effect could be explained by the fact that sensory stimuli, such as touch and warmth, is a powerful vagal stimulant for mother, which releases maternal oxytocin, decreases maternal anxiety, and increases calmness and uterine contraction. Also, neonatal motor activity after SSC over mother's abdomen appears to serve the same function as common medical interventions, such as uterine massage to expel the placenta and to decrease postpartum bleeding. ${ }^{27}$ Neonates among SSC group passed urine more frequently in first 24 hour of life. Increased production of urine in the SSC group most likely reflects more frequent breastfeeding and/or improved milk transfer during breastfeeding in the SSC group. No study in literature has compared this variable.function as common medical interventions, such as uterine massage to expel the placenta and to decrease postpartum bleeding. ${ }^{27}$ Neonates among SSC group passed urine more frequently in first 24 hours of life.

Increased production of urine in the SSC group most likely reflects more frequent breastfeeding and/or improved milk transfer during breastfeeding in the SSC group. No study in literature has compared this variable.

No significant difference was found between the groups with regards to axillary temperature, heart rate and respiratory rate during the first 24 hours of life. Villalon et al . also found no significant difference in axillary temperature at two hours post birth. ${ }^{28}$ These results are in direct contrast to findings of Christensson et al . and Gabriel et al. who found higher axillary temperature in SSC group. ${ }^{26,29,30}$ In these two aforementioned studies, SSC infants had a lower mean heart rate (WMD -3.05 beats per minute (BPM), 95\% CI -7.84 to 1.75) and respiratory rate (WMD -2.76 RPM, 95\% CI -7.29 to 1.77) than control infants who were separated from their mothers. However,

African Health Sciences Vol 16 Issue 3, September 2016 
these results did not reach statistical significance. There was also no significant difference in weight, length and occipito -frontal circumference between two groups at 6 weeks of age. Similarly, Moore et al. did not find differences in infant body weight on postpartum day $14 .{ }^{11}$ Srivastava et al . found better weight gain patterns in SSC group. ${ }^{20}$ Boo et al. has shown better weekly increase in occipito -frontal circumference in very -low -birthweight neonates. ${ }^{31}$ No study in literature has compared length and occipito -frontal circumference in full -term neonates.

The strengths of our study include adequate sample size, randomized controlled study design and concealment of how the groups were allocated. A limitation of this study was that we could not blind the investigator to the nature of intervention. Also, large number of neonates were not enrolled because investigator could not evaluate them immediately after birth (presence of investigator during delivery was an inclusion criteria ). For future research, prolonged follow ups (greater than 6 weeks) may be needed to evaluate the effect of this policy on breastfeeding rates and exclusivity.

\section{Conclusion}

Our study has shown that early SSC significantly improv es the rate of exclusive breastfeeding at 6 weeks of age in healthy term neonates along with decreasing pain during episiotomy repair in mothers. In developing countries, such as India, this simple, inexpensive and non -invasive intervention can increase the rate of exclusive breastfeeding. Therefore, it is recommended that all stable neonates born at term via vaginal delivery should experience SSC soon after birth.

\section{Acknowledgments:}

I gratefully acknowledge Dr Deepak Chawla , Dr Suksham Jain, Dr Veena Parmar and the staff of department of Pediatrics and obstetrics/gynecology, Government medical college, Sector 32, Chandigarh for their assistance.

\section{References}

1. Schmidt B. J. (1983).Breastfeeding and infant morbidity and mortality in developing countries. J. Pediatr. Gastroenterol Nutri., 2 Sup. 1 1: S 127 -130.

2. lawrence RA, Lawrence RM. breastfeeding, a guide for the medical profession.6th ed. Philadelphia: Elsevier, Mosby; 2011.

3.Kliegman RM,Stanton B, Geme JS,Schor N,Behrman
RE. Nelson textbook of pediatrics. 19th ed. Elsevier; 2011: $459-60$.

4. Johnston M, Landers S, Noble L, Szucs K, Viehmann L. Breastfeeding and the use of human milk. Pediatrics 2012; 129(March (3):e827 -41.

5. Ministry of Women and Child Development 2006; National Family Health Survey -3: 274; 10.2.

6. National Family Health Survey -3, India 2005 -06; table no.10.2.1, 10.5, 10.8 .

7. WHO/UNICEF. Protecting, promoting and supporting Breastfeeding: the special role of maternity services, a joint World Health Organization/ UNICEF statement, Geneva, Switzerland; World Health Organization; 1989

8. Gomez P, Baiges N, Batiste F, marca G, Nieto J, Closa M. Kangaroo method in delivery room for full -term babies (in spanish). An Esp Pediatr 1998;48:631 - 3 .

9. Affonso D, Wanlberg V, Persson B. Exploration of mother's reactions to the Kangaroo method of prematurity care. Neonatal Network. 1989; 7(6): 43 -51.

10. Righard L., Alade MO . Effect of delivery room routine on success of first breastfeeding. Lancet. 1990; 336, $1105-7$.

11. Moore ER , Anderson GC, Bergman N . Early skin to skin contact for mothers and their healthy newborn infants. Cochrane Database of Systematic Reviews 2007, Issue 4. Art. No. : CD003519. DOI: 10.1002/14651858. CD003519.pub2.

12. Moore ER, Anderson GC, Bergman N, Dowswell $T$. Early skin -to -skin contact for mothers and their healthy newborn infants. Cochrane Database of Systematic Reviews 2012, Issue 5. Art. No.: CD003519. DOI: 10.1002/14651858.CD003519.pub3.

13. Cancer pain treatment guidelines for patients, version III December 2007. Numerical pain scale. page 10 .

14 . Porter RH, Winberg J. Unique salience of maternal breast odors for newborn infants. Neurosii Biobeh Rev 1999;23:439-49.

15. Porter RH. The biological significance of skin -to -skin contact and maternal odors. Acta Paediatr 2004;93:1560 -2. 16. Righard L, ALade MO. Effect of delivery room routines on success of first breastfeed. Lancet 1990; 336:1105 $-7$.

17. Widstrom AM, Ransjo -Arvidson AB, Chrristensson K. Gastric suction in healthy newborn infants: Effects on circulation and developing feeding behavior. Acta Padiatr Scand 1987;76:566 -72.

18. Langercrantz H, Slotkin TA. The "stress of being born." Sci Am 1986; April: 92 - 102 . 
19. Thukral A, Sankar M, Agarwal R, Gupta N, Deorari A, Paul V. Early Skin -to -Skin Contact and Breast -Feeding Behavior in Term Neonates: A Randomized Controlled Trial. Neonatology. 2012;102:114-119. DOI: 10.1159/000337839.

20. Srivastava S, Gupta A, Bhatnagar A, Dutta S. Effect of very early skin to skin contact on success at breastfeeding and preventing early hypothermia in neonates. Indian J Public Health. 2014 Jan -Mar;58(1):22 -6. doi: 10.4103/0019 -557X.128160.

21. Moore ER, Anderson GC. Randomized controlled trial of very early mother -infant skin -to - skin contact and breastfeedingstatus. J Midwifery Womens Health. 2007 Mar -Apr;52(2):116 -25.

22. Carfoot S, Williamson P, Dickson R. A randomised controlled trial in the north of England examining the effects of skin -to -skin care onbreast feeding. Midwifery. 2005 Mar;21(1):71 -9.

23. Mahmood I, Jamal M, Khan N. Effect of mother -infant early skin to skin contact breastfeeding status: a randomized controlled trial. Journal of the college of Physicians and Surgeons Pakistan 2011;21(10):601 -5. doi: 10.2011/ JCPSP.601605

24. Aghdas K, Talat K, Sepideh B. Effect of immediate and continuous mother -infant skin -to - skin contact on breastfeeding self-efficacy of primiparous women: a randomised control trial. Women Birth. 2014 Mar;27(1):37 -40. 25. Bystrova K, Ivanova V, Edhborg M, Matthiesen AS,
Ransjö -Arvidson AB, Mukhamedrakhimov R, Uvnäs -Moberg K, Widström AM. Early contact versus separation: effects on mother-infant interaction one year later. Birth. 2009 Jun;36(2):97 -109.

26. Marín Gabriel MA, Llana Martín I, López Escobar A, Fernández Villalba E, Romero Blanco I, Touza Pol P. Randomized controlled trial of early skin -to -skin contact: effects on the mother and the newborn. Acta Paediatr. 2010 Nov;99(11):1630 -4.

27. Matteiesen A, Ransjo A, Nissen E, Uvnas K; postpartum maternal oxytocin release by newborns: effect of infant hand massage and sucking. Birth 2001; 28:13 -9.

28. Villalon HU, Aluarez PC. Short term effects of Early skin to skin contact (Kangaroo care) on breastfeeding in healthy full term new borns. Revista Chilena de Pediatrica. 1993; 64(2): $124-8$.

29. Christensson K., Cabrera T., Christensson E., Moberg $\mathrm{K}$., Winberg J: Separation distress call in the human neonate in the absence of maternal body contact. Acta Paediatr. 1995; 84;468 -73.

30. Christenssen K, Siles C, Moreno C, Belanstoqui, De La Fuence, Lagercrantz H, et al. Temperature, metabolic adaptation and drying in healthy full -term new born in skin to skin contact or in a cot. Acta Paediatrica. 1992; 81:488 -93.

31. Boo NY, Jamli FM. Short duration of skin -to -skin contact: effects on growth and breastfeeding. I Paediatr Child Health. 2007 Dec;43(12):831 -6. 